\title{
THE VENUS FLYTRAP: HOW COMMERCIAL NURSERYMEN AND PLANT CONSERVATIONISTS MIGHT CO-OPERATE TO PRESERVE WILD POPULATIONS AND AVOID A FEDERAL LISTING AS ENDANGERED
}

THOMAS GIBSON •205 Danbury Court 2A • De Forest•Wisconsin 53532•USA • thomasgibson187@, gmail.com

Don WaLler - Dept. of Botany - Univ. of Wisconsin-Madison 4430 Lincoln Dr - Madison

-Wisconsin 53706•USA・dmwaller@wisc.edu

Everyone knows the remarkable and unique Venus flytrap (Fig. 1). What many do not know is that populations of this well-known species are highly restricted to a small area of North Carolina and adjacent South Carolina and that these wild populations are going extinct, disappearing before our eyes. For decades, the flytrap was one for the most commercially exploited plants in the United States (Kral 1983: p.545-548) with an estimate of tens of millions being field-collected and sold to the general public after WWII (see Fig. 90 in Evans et al. 2012). Although poaching of plants for illegal

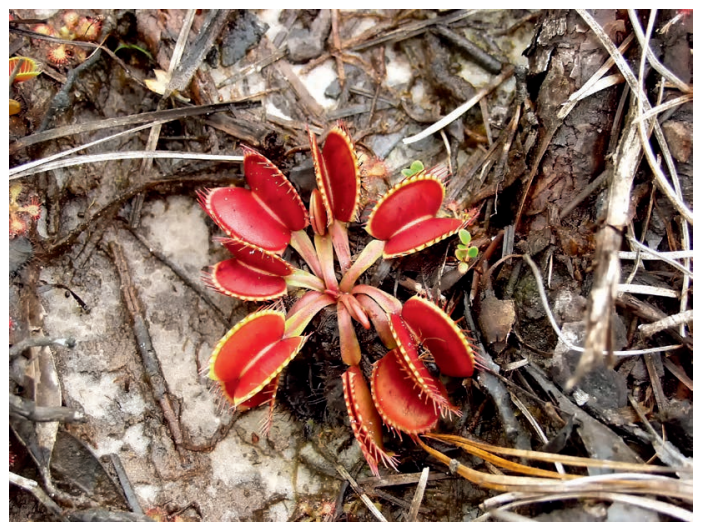

Figure 1: Venus flytrap, Green Swamp, North Carolina. Photo by Jim Fowler with permission. sale continues (Evans et al. 2012), other factors now contribute more to its decline in nature, including habitat destruction, development of its savanna habitats, lack of fire, and drainage of the wet pine savannas. Recent estimates are that just 42 populations of flytraps remain totaling perhaps 86,000 plants (Evans et al. 2012: p.134). Camp Lejeune has a large and dense population, perhaps reflecting the frequency of fire there, but it is not explicitly protected.

These worrying declines in wild populations led to a pending petition requesting the U.S. Fish \& Wildlife Service to list the Venus flytrap as Federally endangered (Waller et al. 2016). Listing the flytrap as Endangered under the 1973 Endangered Species Act (ESA) would clearly benefit wild populations. However, conflicts might arise as listing this plant could interfere with the large commercial market in flytraps. Most of these are commercially propagated via tissue culture, meeting ethical standards, with millions of plants sold each year to the public. An Endangered Listing, however, would prevent or complicate inter-state and international commerce in these plants, potentially threatening the livelihood of some commercial growers and traders of these plants. Restricting legal markets could also favor a black market in flytraps, potentially accelerating the poaching of wild populations.

To resolve potential conflicts in advance, we propose to link commercial trade in flytraps directly with the in situ conservation of wild populations. Most who buy flytraps would readily support conserving wild populations. Why not take advantage of this goodwill by asking every retail buyer to voluntarily pay a $\$ 0.25$ to $\$ 0.50$ surcharge on each Venus flytrap sold? This would involve asking commercial nurserymen to affirm that they have ethically propagated the flytraps and setting up a small program to confirm these certifications. Most nurseries are already following ethical practices 
that protect wild populations. By participating in a public campaign to sustain wild populations of this species, they would broaden public appreciation and concern for the species and possibly expand the overall market. Given the volume of sales of flytraps, this source of revenue could amount to millions of dollars per year, enough to both administer the program and acquire and protect the wet longleaf pine habitats that sustain wild flytrap populations.

To make this program visible, plants from participating sources would carry a special brightlycolored tag signaling their ethical source and informing buyers how they are supporting the conservation of wild Venus flytraps. The tag and program would signal buyers as to which growers are responsible and concerned. The tag would also include a web URL so those interested could learn more about the biology and conservation of flytraps. The program could be rolled out with publicity and a press release to raise awareness about the plight of wild populations and to build public support for the surcharge.

A Board including both participating commercial nursery growers and leading plant conservationists would direct and oversee the program, ensuring that the funds collected were wisely disbursed to efficiently protect existing populations. Funds raised in this way could be used to purchase and protect additional lands, augment depleted populations, and manage and restore degraded habitats by protecting the hydrology of habitats and burning them as needed to rejuvenate populations. While some commercial nurserymen might be indifferent to protecting flytrap populations in nature, those participating could advertise their participation to signal their concern, potentially increasing their market among concerned buyers and thus revenue. As the public became more aware and concerned, market pressure on other growers to join the program would grow. Efforts to inform and involve the public could speed this transition, as outlined below.

Note that no new laws or government regulations are needed to implement this proposal - simply the interest and will of growers and conservationists, working collaboratively on a goal they both support. Note further that this model could easily spread internationally to other countries, particularly in Europe where the public is highly concerned about conservation. Furthermore, if this program were voluntarily implemented and successful, it could provide the basis for an effective Habitat Conservation Plan. Under an amendment to the original 1973 ESA, implementing a Habitat Conservation Plan provides an alternative that reduces the stringent provisions of the ESA, e.g., by allowing some "incidental take" of individuals as long as populations are secure. It is also possible to design and implement an HCP in advance of Listing, allowing the U.S. Fish \& Wildlife Service to assign the species a lower level of protection (e.g., Threatened) or even to defer listing altogether.

\section{Program to promote public participation}

To ask the public to buy only plants which have the surcharge and tag, it will be important to inform them about certain key points including:

Why can't the flytrap just be preserved via cultivation?

The general public needs to understand propagating large numbers of potted Venus flytraps does nothing by itself to ensure the survival of the species. The only safe place for flytraps in the long run is in nature. Relying on cultivation would fail to preserve the flytrap for several reasons. First, the flytrap, like any other species, exists in an ecological and evolutionary context. If those contexts are lost, so is the species. Growing plants in cultivation in botanical gardens and hobbyist collections removes that context. Instead of natural selection, plants become subject to artificial selection favor- 
ing plant genotypes that thrive under greenhouse conditions. Cultivated flytraps gradually resemble their wild counterparts less and less due to this inadvertent artificial selection.

Commercially grown flytraps may also become susceptible to disease including potential new pathogens which could quickly spread to infect most plants. In hobbyist collections, plants often die due to neglect or loss of interest. Botanic gardens change curators, plants get thrown out, and expertise can be lost. Finally, we cannot guarantee that propagated plants will persist. The next major recession or a war could quickly destabilize economies, trade, and society causing millions of plants to be lost.

Is listing the flytrap as federally endangered justified? Would its listing ensure that its populations are conserved?

Wild flytrap populations have declined greatly since the $1980 \mathrm{~s}$ - for many reasons (Waller et al. 2016). These declines, coupled with its narrow geographic range and susceptibility to future habitat loss and encroachment, are the basis for the petition to list this species as Federally Endangered. Listing the Venus flytrap as endangered would trigger some protections including an analysis to designate critical habitat, possible funds for land acquisition, and efforts to manage and restore populations, e.g. using fires. While the Endangered Species Act has proved to be very effective at protecting and promoting the recovery of certain species (e.g., the bald eagle), it also has clear shortcomings, particularly for plants. These include the fact that Congress has historically underfunded endangered species programs, slowing how quickly they can be reviewed and listed and limiting funds for assessing and managing critical habitat for these species. Plants, in particular, wait very long times during the listing process and afterwards for these protections. Once a plant is listed as Endangered, it also typically receives only a small fraction of the staff time and budget that endangered mammals and birds receive. The Trump Administration severely cut funds to Endangered Species programs. Listings are now taking 6 years or more, slowing any federal assistance for this plant but also affording time to work together to institute the voluntary fee and generate a Habitat Conservation Plan. This makes more sense in any case than waiting for populations to decline further with only uncertain funds in the future.

It is also a surprise to many that endangered plants are not protected to the same degree as endangered animals. Anyone harming an endangered animal in any context is subject to stiff fines and penalties. In contrast, endangered plants growing on private lands gain no protection from exploitation (for reasons that go back to English Common Law). Thus, flytraps growing on private lands will not receive any protection even if they are listed (though trade in such plants would be restricted). Finally, the Endangered Species Act is a blunt instrument, requiring elaborate procedures that could interfere with trade even as on-the-ground management falters. Our shared goal here should be protecting wild populations.

Avoiding conflict over a Federal listing as Endangered.

The Endangered Species Act prohibits trade in listed species across state lines, even if they are ethically propagated. Thus, the ESA has the potential to shut down all commercial U.S. traffic in flytraps. The Lacey Act Amendment for plants does the same thing, making it a violation of the Amendment if the ESA is violated. Listing the flytrap as endangered in the U.S. could also trigger provisions in the international CITES treaty restricting international transport and trade in endangered species. To avoid these consequences, it would be best to foster co-operation between wholesale commercial growers and plant conservationists. Given their shared interests, it would behoove them to organize in advance of any formal listing of the flytrap as Federally Endangered. 
They might also jointly hire attorneys to explore whether there may be a way to minimize impacts of a listing on commercial nurseries and sellers. It may also make sense to mobilize a campaign to inform growers of the situation, allow them to meet and discuss the situation, and invite them to contribute comments to the Federal Register.

A Nation-wide Campaign to save the Venus flytrap, as run by a non-profit conservation organization.

The surcharge we propose could provide immediate and substantial funds for protecting wild populations of the flytrap. In essence, the general public saves wild Venus flytrap populations by buying propagated and ethical plants. All that is needed is the will, a publicity campaign, and a fair mechanism to implement a structure (a committee of commercial nurserymen and plant conservationists) to oversee the program and spend the funds generated. The campaign is needed to publicize the plight of wild populations, raise awareness of how to save the flytrap, and encourage people to buy plants showing the tag with the surcharge.

A non-profit conservation organization might run the campaign. We are searching for one now.

This non-profit conservation organization, if it sponsored this campaign, might organize the approximately 81 commercial flytrap wholesale growers into a powerful political force in favor of protecting wild populations. I believe the most effective vehicle to do this is through 'Change. org" as a series of petitions to commercial wholesale growers along with an ad campaign directed towards the general public. It might also set up a hotline for commercial wholesale growers, hobbyists, the general public, and garden centers across the nation. The hotline would provide information on all aspects of the national-wide campaign. The phone number of this hotline might be placed prominently on the surcharge tag on each potted plant sold.

What you can do to help benefit wild populations in nature?

If you care about protecting the remaining wild Venus flytrap populations, you might:

1. Get the correct facts from those concerned with these efforts. Discern the truth to the best of your ability; both sides in this potential conflict are right and both sides are wrong.

2. Write your viewpoints in a Formal Comment to the Federal Register (federalregister.gov).

3. Request conflict resolution and co-operation if the conflict starts.

4. Share this article and information with commercial wholesale nurserymen who propagate the flytrap, garden centers which retail sale flytraps, online suppliers of flytraps for sale, and botanic gardens which exhibit flytraps. Schools sometimes exhibit flytraps to teach students and should be approached also with information.

5. Apply pressure on non-compliant growers by asking them how they feel about the situation and what they are doing to help save the flytrap.

6. Start a petition with "Change.org" to apply pressure on well-known outlets to voluntarily join this campaign. The petitions should emphasize the positive financial benefits of joining this campaign to protect the flytrap; companies should not be punished for selling ethically produced flytraps.

7. Help organize the campaign locally in your town or city by going to garden centers and botanic gardens and asking what they are willing to do for it.

Conclusion

Although almost everyone in the United States knows what the Venus flytrap looks like and how its snap-traps behave, very few have ever seen its pretty wetland savanna habitats covered with 
thousands of plants displaying their red miniature bear-traps - a remarkable and awe-inspiring sight. It is worthwhile to engage those who grow the flytrap with great pleasure to become more familiar with the beauty of its disappearing habitats, its particular ecology that makes them dependent on these habitats, and their bleak fate as populations disappear, threatening this marvelous plant with extinction. For those who love nature and the flytrap, preserving wild populations and managing their habitats must become a priority. To protect these remarkable plants from harm, we must think beyond the fun of growing one or a few in a pot to invent a vehicle for saving these plants in nature. This will require growers, plant-loving hobbyists, and plant conservationists to think creatively and cooperate on programs that can work.

Acknowledgements: Many people shared ideas, discussed these topics, and provided suggestions and edits. TCG dedicates this paper to the staff at Crisis Intervention, a mental health hotline, with deep respect and love.

\section{References}

Evans, R., Gibson, T., and Johnson, Y. 2012. Conservation Status. In: Bailey, T., and McPherson, S. Dionaea - The Venus's Flytrap. Redfern Natural History Productions Ltd, pp 127-141.

Gibson, T.C., and Waller, D.M. 2009. Evolving Darwin's 'most wonderful' plant: ecological steps to a snap-trap. The New Phytologist 183(3): 575-587.

Kral, R. 1983. A Report on Some Rare, Threatened, or Endangered Forest-Related Vascular Plants of the South. Vol. 1. Isoetaceae through Euphorbiaceae. U.S. For. Serv. Tech. Publ. R8-TP2. Atlanta, Georgia.

Waller, D.M., Evans, R., Gibson, T., and Johnson, Y.B. October 21, 2016. Petition to list the Venus flytrap (Dionaea muscipula Ellis.) as Endangered under the 1973 Endangered Species Act. Before the Secretary of the Interior, Federal Government, Washington, D.C.

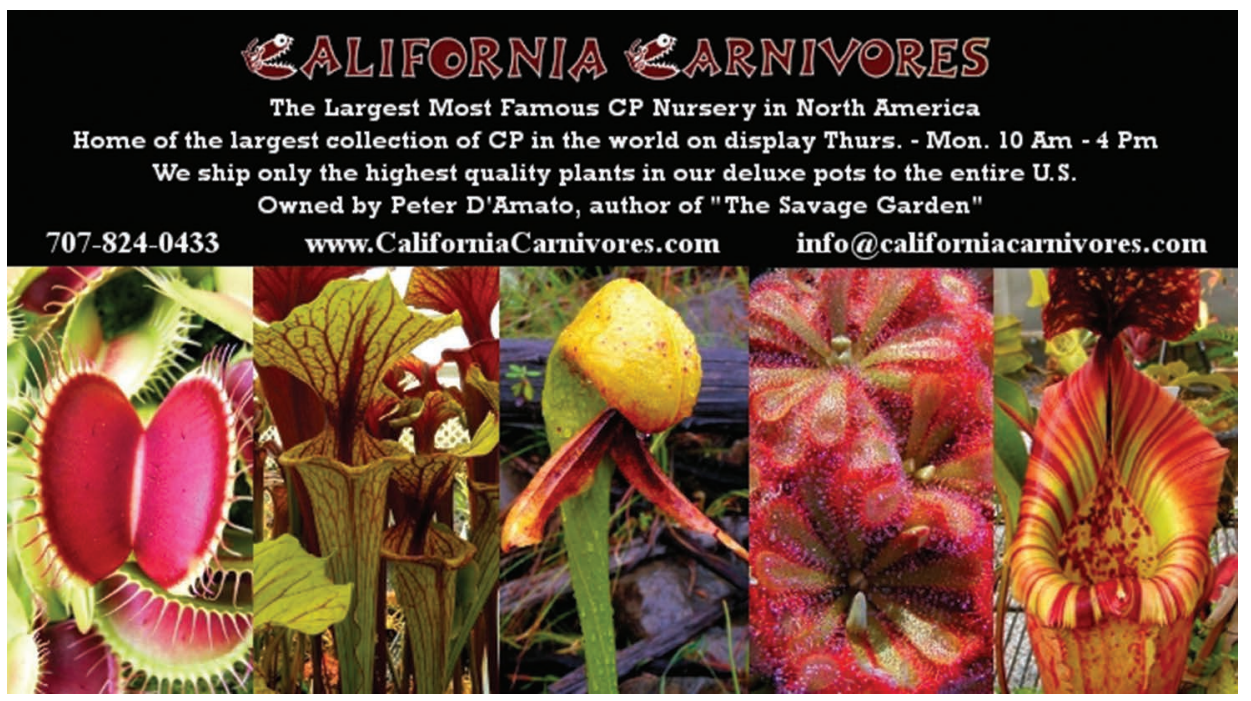

